\title{
Relationship between Signal Intensity Change of the Spinal Cord on MRI and Motor Myelopathic Severity in Patients with Cervical Spondylotic Myelopathy
}

\author{
Kanij Fatema Ishrat Zahan', M Afzal Hossain², Kanak Kanti Barua ${ }^{3}$, \\ ATM Mosharef Hossain ${ }^{4}$, Abul Khair ${ }^{5}$, M Mozammel Hoque 6 \begin{abstract}
${ }^{2}$ Professor \& Chairman, Department of Neurosurgery, Bangabandhu Sheikh Mujib Medical University, Dhaka,
Bangladesh; ${ }^{3}$ Professor, Department of Neurosurgery, Bangabandhu Sheikh Mujib Medical University, Dhaka, Bangladesh; ${ }^{4}$ Professor, Department of Neurosurgery, Bangabandhu Sheikh Mujib Medical University, Dhaka, Bangladesh; ${ }^{5}$ Professor, Department of Neurosurgery, Bangabandhu Sheikh Mujib Medical University, Dhaka, Bangladesh; ${ }^{6}$ Professor, Department of Biochemistry, Bangabandhu Sheikh Mujib Medical
\end{abstract} \\ ${ }^{1}$ Indoor Medical Officer, Department of Neurosurgery, Dhaka Medical College Hospital, Dhaka-1200, Bangladesh; \\ University, Dhaka, Bangladesh.
}

[Received: May 2014; Reviewed: March 2015; Accepted: June 2015; Published: July 2015]

\begin{abstract}
Background: Diagnosis of cervical spondylotic myelopathy (CSM) can be challenging due to subtle symptoms and insidious onset; however, there is a relationship between signal intensity change of the spinal cord on MRI and cervical spondylotic myelopathy. Objective: The purpose of this present study was to find out the relationship between signal intensity change of the spinal cord on MRI and motor myelopathic severity in patients with CSM. Methodology: This cross-sectional study was carried out in the Department of Neurosurgery at Banghabandhu Sheikh Mujib Medical University (BSMMU), Dhaka from October, 2011 to March, 2013 for a period of one and half year. All patients presented with cervical spondylotic myelopathy were included in this study. MRI of cervical spine was performed to all patients. Results: A total number of 36 patients with cervical spondylotic myelopathy were included in this study. Among the 36 study patients, all had normal intensity in the spinal cord on sagittal $\mathrm{T}_{1} \mathrm{WI}$ of MRI; however, there was variable intensity on sagittal T2WI of MRI. Low Nurick score was found in 24(66.6\%) patients who had type 0 signal intensity on $\left(\mathrm{T}_{2} \mathrm{WI}\right)$ MRI. High Nurick score was found in $3(8.3 \%)$ patients who had type 0 signal intensity on ( $\mathrm{T}_{2} \mathrm{WI}$ ) MRI. Low Nurick score was found in 2(5.5\%) patients who had type 1 signal intensity on (T2WI) MRI. High Nurick score was found in 6(16.6\%) patients who had type 1 signal intensity on ( $\left.\mathrm{T}_{2} \mathrm{WI}\right) \mathrm{MRI}$. Only 1 patient (2.7\%) having high Nurick score (3-5) had type-2 signal intensity on ( $\left.\mathrm{T}_{2} \mathrm{WI}\right)$ MRI ( $\mathrm{p}<0.001)$. Conclusion: There is a direct relationship between signal intensity change of the spinal cord on MRI and motor myelopathic severity in patients with cervical spondylotic myelopathy. [Journal of National Institute of Neurosciences Bangladesh, 2015;1(2): 37-40]
\end{abstract}

Keywords: Signal intensity change (SIC); motor myelopathic severity; Spinal cord; MRI; cervical spondylotic myelopathy (CSM)

Correspondence: Dr. Kanij Fatema Ishrat Zahan (Rifat), Indoor Medical Officer, Department of Neurosurgery, Dhaka Medical College Hospital, Dhaka-1200, Bangladesh; Email: kfizrifat@gmail.com; Cell no.:+8801815419671

Conflict of interest: There is no conflict of interest to any of the authors of this article.

Funding agency: The study was not funded by any authority.

Contribution to authors: KFIZ, MAH, KKB, ATMMH \& AK were involved in protocol preparation, data collection and literature search up to report writing. MMH was involved in manuscript preparation as well as involved in literature search up and manuscript revision and also in statistical analysis.

How to cite this article: Zahan KFI, Hossain MA, Barua KK, Hossain ATMM, Khair A, Hoque MM. Relationship between Signal Intensity Change of the Spinal Cord on MRI and Motor Myelopathic Severity in Patients with Cervical Spondylotic Myelopathy. J Natl Inst Neurosci Bangladesh, 2015;1(2): 37-40

\section{Introduction}

Dorsomedial herniation of a disc and the development of transverse bony bars or posterior osteophytes may result in pressure on the spinal cord or the anterior spinal artery which supplies the anterior two-thirds of the cord is called cervical spondylotic 
myelopathy ${ }^{1}$.Cervical spondylotic myelopathy (CSM) represents a spectrum of pathologies that start with progressive degeneration of the disc, leading to instability at the posterior joints and spur formation and are associated with hypertrophy of the ligamentum flavum, resulting in stenosis of the cervical canal circumferentially ${ }^{2}$.

Regarding natural history, onset of cervical spondylosis is insidious but a slow deterioration occurs in $20 \%$ of patients, $5.0 \%$ remain static and $75.0 \%$ develop new symptoms and signs ${ }^{3}$. Males around age 50 with a history of chronic occupational neck trauma are thought to be commonly afflicted. Initial complaints such as the inability to discern coins when removing change from one's pocket, difficulty in buttoning a shirt, tying a necktie, or fastening the clasp of a bra are common. Associated symptoms include subjective numbness, tingling and weakness in the hands ${ }^{4}$. Numbness and tingling can follow a root pattern: thumb for $\mathrm{C}_{6}$, middle finger for $\mathrm{C}_{7}$ and little finger for $\mathrm{C}_{8}{ }^{3}$. Motor myelopathic signs are defined as the presence of hyperreflexia (Reflex $\geq$ grade 3 ) or provocative signs which specifically includes Hoffmann's sign, inverted brachioradialis reflex (IBR), sustained clonus (more than 3 beats) and Babinski sign. Reflexes are graded on a 0 to 4 scale like 0 means absent, 1 means hypoactive, 2 means normal, 3 means hyperactive without clonus, 4 means very hyperactive, often with clonus ${ }^{5}$.

The delineation of cervical spondylotic myelopathy as a clinical entity has improved with the development of high-quality cross-sectional neuroradiologic imaging? Among the various imaging modalities used in clinical practice, MRI pathophysiologic specificity and potential for repeat studies without adverse effects on the health of subjects, is often the method of choice ${ }^{8}$. Sagittal views clearly demonstrate cord compression at the level of the disc space. Any hyperintensity within the cord on $\mathrm{T}_{2}$ weighted image reflects cord damage and may correlate with the severity of the myelopathy and outcome? .

Increased signal intensity (ISI) within the cervical cord on $\mathrm{T}_{2}$-weighted MR images obtained in patients with CSM was initially noted. More recently, 3 types of ISI changes have been identified on sagittal $\mathrm{T}_{2}$-weighted MR images which are based on ISI characteristics as no change (Type 0), faint, fuzzy changes (Type 1) and intense, sharp changes (Type 2).This categorization of changes on sagittal $\mathrm{T}_{2}$-weighted images is based on the sharpness of the margins and the degree of hyperintensity of the intramedullary changes. Intramedullary signal changes that are dull or light and have an unclear margin are termed "fuzzy" changes or

Type 1 changes and those that are brilliant or intense and are clearly defined are termed "sharp" or Type 2 changes ${ }^{10}$. The objective of this present study was to find out the relationship between signal intensity change of the spinal cord on MRI and motor myelopathic severity in patients with CSM.

\section{Methodology}

The cross sectional study was conducted in the Department of Neurosurgery at Bangabandhu Sheikh Mujib Medical University (BSMMU) Hospital, Dhaka, Bangladesh from October 2011 to March 2013 for a period of one and half year. Patients who were diagnosed as a case of CSM both clinically and on MRI of cervical spine who were admitted in the department of Neurosurgery, BSMMU were included as study population. All the relevant data were recorded in a predesigned data sheet. Data were collected purposively and analyzed by using the computer based software Statistical Package for Social Sciences, (SPSS, version 16.0). Chi square test was applied to assess the relationship between signal intensity change of the spinal cord on MRI and motor myelopathic signs in the respondents. Statistical significance was set at $p$ value $<0.05$.

\section{Results}

A total number of 36 patients with cervical spondylotic myelopathy were recruited for this study after fulfilling the inclusion and exclusion criteria.

Table 1: Distribution of the Respondents by Presenting Complaints (multiple responses)

\begin{tabular}{lcc}
\hline Complaints & Frequency & Percentage \\
\hline Neck pain & 9 & 25.0 \\
Numbness \& tingling sensation & 18 & 50.0 \\
Weakness in upper limbs & 34 & 94.4 \\
Gait dysfunction & 11 & 30.5 \\
Difficulty in buttoning & 9 & 25.0 \\
\hline
\end{tabular}

The patients have multiple responses like if one patient had weakness in upper limbs, he or she might have neck pain or numbness \& tingling sensation. Among the total respondents, presentation with weakness in upper limbs was found in 34(94.4\%) patients followed by numbness $\&$ tingling sensation was in $18(50.0 \%)$ patients and gait dysfunction was in $11(30.5 \%)$ patients. Neck pain \& difficulty in buttoning were in $9(25.0 \%)$ patients (Table $1)$. 
Table 2: Distribution of the Respondents by Presence of Motor Myelopathic Signs (multiple responses)

\begin{tabular}{lcc}
\hline Motor myelopathic signs & Frequency & Percentage \\
\hline Hyperreflexia & 36 & 100.0 \\
IBR & 1 & 2.7 \\
Hoffmann's sign & 27 & 75.0 \\
Ankle clonus & 9 & 25.0 \\
Babinski sign & 34 & 94.4 \\
\hline
\end{tabular}

The respondents have multiple responses like if one patient had hyperreflexia, he or she might have Hoffmann's sign or any other motor myelopathic signs. Among the total respondents, 36(100.0\%) patients had hyperreflexia followed by 34(94.4\%) patients had Babinski sign, 27(75.0\%) patients had Hoffmann's sign, 9(25.0\%) patients had Ankle clonus and 1(2.7\%) patient had IBR (Table 2).

Table 4: Relationship between signal intensity in the spinal cord on (T2WI) MRI and severity of motor myelopathic signs in the respondents

\begin{tabular}{lccl}
\hline Signal intensity on & \multicolumn{2}{c}{ Nurick Score } & P value \\
\cline { 2 - 3 }$\left(\mathbf{T}_{2} \mathbf{W I}\right)$ MRI & $\begin{array}{c}\text { Low score } \\
\mathbf{( 0 - 2 )}\end{array}$ & $\begin{array}{c}\text { High score } \\
\mathbf{( 3 - 5 )}\end{array}$ & \\
\hline Type 0 & 24 & 3 & \\
Type 1 & 2 & 6 & \\
Type 2 & 0 & 1 & $<\mathbf{0 . 0 0 1}$ \\
Total & $\mathbf{2 6}$ & $\mathbf{1 0}$ & \\
\hline
\end{tabular}

Among the total respondents, 26 patients $(72.2 \%)$ had low Nurick score (0-2) followed by 10 patients $(27.8 \%)$ had high Nurick score (3-5) (Table 3).

Table 3: Distribution of the respondents according to severity of motor myelopathic signs $(n=36)$

\begin{tabular}{lcc}
\hline $\begin{array}{l}\text { Severity determined } \\
\text { by Nurick score }\end{array}$ & Frequency & Percentage \\
\hline Low score(0-2) & 26 & 72.2 \\
High score (3-5) & 10 & 27.8 \\
Total & $\mathbf{3 6}$ & $\mathbf{1 0 0 . 0}$ \\
\hline
\end{tabular}

Low Nurick score was found in 24(66.6\%) patients who had type 0 signal intensity on $\left(\mathrm{T}_{2} \mathrm{WI}\right)$ MRI. High Nurick score was found in 3(8.3\%) patients who had type 0 signal intensity on $\left(\mathrm{T}_{2} \mathrm{WI}\right)$ MRI. Low Nurick score was found in $2(5.5 \%)$ patients who had type 1 signal intensity on $\left(\mathrm{T}_{2} \mathrm{WI}\right)$ MRI. High Nurick score was found in $6(16.6 \%)$ patients who had type 1 signal intensity on $\left(\mathrm{T}_{2} \mathrm{WI}\right)$ MRI. Only 1 patient $(2.7 \%)$ having high Nurick score (3-5) had type-2 signal intensity on $\left(\mathrm{T}_{2} \mathrm{WI}\right)$ MRI. The difference was statistically significant $(\mathrm{p}<0.001)$ (Table 4).

\section{Discussion}

This study included only patients with cervical spondylotic myelopathy (CSM) diagnosed both clinically and on MRI of cervical spine done minimum at 1.5 Tesla MRI who were admitted in the Department of Neurosurgery at BSMMU, Dhaka. Relationship between signal intensity change of the spinal cord on MRI and motor myelopathic severity was the prime focus of this study.

CSM usually occurs in patients around 50 years. Chatley et $\mathrm{al}^{12}$ found that in their series of 67 patients with CSM the mean age was 47.1 years with a range of 22 to 65 years. In this study, the mean age was 53.11 years with SD of \pm 10.71 years. The range of age in this series of 36 patients was 30 to 72 years. Maximum numbers of study patients $(30.6 \%)$ were in between 40 to 49 years followed by between 50 to 59 years which was $27.8 \%$ cases. In another study, the study population was composed of 67 patients whose mean age was 59.5 years with an age range of 30 to 79 years ${ }^{13}$.

In this study, sex distribution of the patients revealed male being $80.6 \%$ (29) and female $19.4 \%$ (7). Male to female ratio was 4.2:1. Similarly in the study of Chatley et $\mathrm{al}^{12}$ among 64 patients, 57 were male and 7 were female giving male to female ratio as 8.14:1. In another study, the study population was composed of 67 patients among whom 17 were female and 50 were male ${ }^{13}$.

This study shows the presenting symptoms among the respondents in descending order as weakness in upper limbs (94.4\%), numbness \& tingling sensation $(50.0 \%)$, gait dysfunction $(30.5 \%)$, neck pain $(25.0 \%)$ and difficulty in buttoning $(25.0 \%)$. The respondents have multiple responses, like if one patient had weakness in upper limbs, the patient may also have had neck pain or numbness \& tingling sensation. Chatley et $\mathrm{a}^{12}$ shows the presenting complaints in their study as gait dysfunction (86.0\%), limb weakness (78.1\%), numbness \& tingling (51.6\%) and neck pain (39.1\%).

In this present study, there were 5 motor myelopathic signs being present in the respondents named hyperreflexia, Hoffmann's sign, IBR (Inverted brachioradialis reflex), ankle clonus and Babinski sign. All the study patients $(n=36)$ had hyper reflexia $(100 \%)$. Babinski sign was present in $27(94.4 \%)$ number of study patients. positive Hoffmann's sign was present in $27(75 \%)$ patients followed by $9(25 \%)$ 
patients had ankle clonus. IBR was found in $2.7 \%$ patients only. The respondents have multiple responses, i.e. if one patient had hyperreflexia, the patient might have Hoffmann's sign or any other motor myelopathic signs. In another study, hyperreflexia was present in $85.19 \%$ cases, Hoffmann's sign was $83.33 \%$ cases and Babinski sign was in $44.44 \%$ cases $^{14}$. Chikuda et $\mathrm{al}^{15}$ also found in their study as hyperreflexia being 96\%, Hoffmann,s sign $80 \%$, Babinski sign $52 \%$ and ankle clonus $28 \%$. In another study, there were Hoffmann's sign was in $59 \%$ cases, hyperreflexia was in $62 \%$ cases, IBR was in $51 \%$ cases, Babinski sign was in $13 \% \%$ and ankle clonus was in $13 \%$ cases $^{5}$.

In this study, severity of motor myeopathic signs has been determined by Nurick score. In one study it was shown that prevalence of the motor myelopathic signs correlated with the severity of cervical spondylotic myelopathy ${ }^{15}$. In this study, all the respondents had normal signal intensity on T1WI of MRI. About 75\% study patients had Type- 0 signal intensity change in the spinal cord on $\mathrm{T}_{2} \mathrm{WI}$ of MRI followed by $22.2 \%$ patients had Type-1 signal intensity change in the spinal cord on $\mathrm{T}_{2} \mathrm{WI}$ of MRI and only $2.8 \%$ patients had Type-2 signal intensity change in the spinal cord on $\mathrm{T}_{2} \mathrm{WI}$ of MRI.

In another study, there were $46.7 \%$ Type- 0 signal intensity change in the spinal cord on $\mathrm{T}_{2} \mathrm{WI}$ of MRI followed by $38.5 \%$ Type-1 signal intensity change in the spinal cord on $\mathrm{T}_{2} \mathrm{WI}$ of MRI and $25.4 \%$ Type- 2 signal intensity change in the spinal cord on $\mathrm{T}_{2} \mathrm{WI}$ of MRI $^{11}$.

In this study, all the respondents had normal intensity in the spinal cord on $\mathrm{T}_{1} \mathrm{WI}$ of MRI, but variable intensity on $\mathrm{T}_{2} \mathrm{WI}$. So, we assessed the relationship between signal intensity in the spinal cord on $\mathrm{T}_{2} \mathrm{WI}$ of MRI and severity of motor myelopathic signs in the patients which was determined by Nurick score. Study patients having low Nurick score (0-2) had Type-0 signal intensity change and those having high Nurick score (3-5) had either Type-1 or Type-2 signal intensity change in the spinal cord on $\mathrm{T}_{2} \mathrm{WI}$ of MRI which is statistically highly significant $(p<0.001)$. As this study was for a short period of time and being small consisting of limited number of patients, it may not be possible to generalize the findings to reference population.

\section{Conclusion}

In conclusion there is a direct relationship between signal intensity change of the spinal cord on MRI and motor myelopathic severity in patients with cervical spondylotic myelopathy.

\section{References}

1. Colledge NR, Walker BR, Ralston SH. Neurological disease: Disorders of the spine and spinal cord. In: Colledge, N. R., Walker, B. R. \& Ralston, S. H. (eds.) Davidson's Principles \& Practice of Medicine. 21st ed. Edinburgh: Churchill Livingstone: Elsevier 2010, 1241-1242

2. Wazir NN, Kareem BA. New clinical sign of cervical myelopathy: Wazir hand myelopathy sign. Singapore Med J 2011;52:47-49

3. Samandouras G. Cervical spondylosis. In: Samandouras G. (ed.) The Neurosurgeons Handbook. 2nd ed. New York : Oxford University Press 2010., 811-812.

4. Rumi MN, Yoon ST. Cervical Myelopathy: History and Physical Examination. Spine Surgery 2004;16:234-240

5. Rhee JM, Heflin JA, Hamasaki T, Freedman B. Prevalence of physical signs in cervical myelopathy: a prospective, controlled study. Spine 2009;34(9):890-895

6. Vitzthum HE, Dalitz K. Analysis of five specific scores for cervical spondylogenic myelopathy. Eur Spine J 2007;16:2096-2103

7. Emery SE. Cervical spondylotic myelopathy: diagnosis and treatment. J Am Acad Orthop Surg 2001;9(6):376-388

8. Panigrahy A, Nelson MD, Bluml S. Magnetic resonance spectroscopy in pediatric neuroradiology: clinical and research applications. Pediatr Radiol 2010;40:3-30

9. Lindsay KW, Bone I, Fuller G. Cervical Spondylosis. In: Lindsay, K. W., Bone, I. \& Fuller, G. (eds.) Neurology And Neurosurgy Illustrated. 5th ed. London: Elsevier, 2010, 412-414

10. Vedantam A, Jonathan A, Rajshekhor V. Association of magnetic resonance imaging signal changes and outcome prediction after surgery for cervical spondylotic myelopathy. J Neurosurg Spine 2011;15:660-666.

11. Morio Y, Teshima R, Nagashima H, Nawata K, Yamasaki D, Nanjo Y. Correlation between operative outcomes of cervical compression myelopathy and mri of the spinal cord. Spine 2001;26:1238-1245

12. Chatley A, Kumar R, Jain VK, Behari S, Sahu RN. Effect of spinal cord signal intensity changes on clinical outcome after surgery for cervical spondylotic myelopathy. J Neurosurg Spine 2009;11;562-567 13. Rota JJFD, Meschian S, Rota AFD, Urbano V, Baron M. Cervical spondylotic myelopathy due to chronic compression: the role of signal intensity changes in magnetic resonance images. J Neurosurg Spine 2007;6:17-22

14. Harrop JS, Naroji S, Maltenfort M, Anderson DG, Albert T, Ratliff JK, Ponnappan RK, Rihn JA, Smith HE, Hilibrand A, Sharan AD, Vaccaro A. Cervical Myelopathy: A Clinical and Radiographic Evaluation and Correlation to Cervical Spondylotic Myelopathy. Spine 2010;35(6):620-624

15. Chikuda H, Seichi A, Takeshita K, Shoda N, Ono T, Matsudaira K, Kawaguchi H, Nakamura K. Correlation between pyramidal signs and the severity of cervical myelopathy. Eur Spine J 2010;19:1684-1689 